\title{
A Probe into the Status of global countries' Trade Positions in the Global Value Chain (GVC) - based on Value Added Trade Perspective and Network Modeling ${ }^{1}$
}

\author{
Fathin Faizah Said ${ }^{2}$, Ming Fang ${ }^{3}$
}

\begin{abstract}
:
This study is concentrated on measuring the global value chain (GVC) using value added trade based on the network topology of bilateral trade specifically for 62 global economies listed in the WTOOECD database. Intermediate trade has become the trend in global international trade which has occupied $63 \%$ of the total world trade. This study will intuitively observe the status of global countries' positions in the international network. Value added trade has been used for measuring a country's participation in GVC replacing the traditional index. Network analysis will be used to analyze the world trade pattern in 1995, 2000, 2005, 2008, 2009, 2010 and 2011 for a total of seven years. Our findings show that the global trade network is interconnected and more countries have established international trade relationship. In addition, distribution of global trade is still concentrated in a few countries, but the degree of power is declining; the heterogeneity of export is slightly higher than the import heterogeneity, which indicates that trade export is more dispersive than import. We also found that China, Russia, India, and Saudi Arabia became new core countries in 2011 and the position of the USA, Japan, Germany, the United Kingdom are stable. The position of Korea and Mexico slightly decreased while Malta, Lithuania, Cyprus, Cambodia, Latvia, Iceland, and other countries are still maintained in the periphery area.
\end{abstract}

Keywords: global trade network, value added method, global value chain

JEL Classifications: C63, G21

\section{Introduction}

Global Value Chains (GVCs) with large intermediate trade refers to close and complex global trade links between countries. Lamy and Shiraishi (2011) noted that the current production has become "made in the world". Milberg, Jiang, and Gereffi (2014) found that the final product of the production goes through two or more links, which are distributed in two or more countries and produce value added trade in various processes of production. At present, about $60 \%$ of the world trade is composed of intermediate trade as a large proportion of the intermediate trade.

Under the global value chain, the traditional calculation of international trade cannot really reflect the true situation of one country's economic status. This perhaps the reason why WTO statistical officers, Maurer and Degain (2010), have stated that "what you see is not what you get" and also said that a better measurement can help to provide more relevant and reliable information to policy-makers. Koopman, Powers, Wang and

${ }^{1}$ This article is funded by Faculty of Economics and Management, Universiti Kebangsaan Malaysia, 43600 Bangi, Selangor, Malaysia.

${ }^{2} \mathrm{Ph} . \mathrm{D}$., Senior Lecturer, School of Economics, Faculty of Economics and Management, Universiti Kebangsaan Malaysia, 43600, Bangi Selangor, Malaysia.

${ }^{3}$ Lecturer, Xi'an Eurasia University, Dongyi Road 8, Yanta District, Xi'an, Shannxi, China. 
Wei (2008) argued that there are some limitations in traditional methods: First, it duplicates statistics of intermediate products leading to overestimation of the trade level of a country, due to large numbers of intermediate goods crossing countries' borders; second, inaccurate trade statistics would lead to the misunderstanding of one country's international specialization status; third, inaccurate judgments of trade status and trade patterns makes a country's current trade policy ineffective. When the policy makers make the appropriate policy instructions based on inaccurate results, it inevitably cannot achieve the government's expected effect, leading to the failure of the policy effect. Therefore, accurate measurement of the value chain of exporting countries is the key to better understanding the above issues (Koopman et al., 2008). Therefore, in this study we will be using the database provided by WTO-OECD in calculating value added trade replacing the traditional method. This database has been supplemented by global value chain data since 2008. It includes integrating the global trade data of 62 countries over seven years. The publication of the database has greatly contributed to the value added trade (trade in value added) applications. The problem of intermediate product repetition statistics and the source of value added in the current trade statistics system can be solved by means of the value added of trade statistics as opposed to the methods of Koopman, Powers, Wang, and Wei (2010).

In the real world, behavior of each agent in the economy is interconnected. To integrate with the complexness of the real world situation, network analysis has become crucial in mapping the bilateral trade between the countries in the world. The network analysis can be used to map who is linked to whom and how much trading could contribute to the economy. Therefore, we can provide a visualization and topology structure of which country is contributing a large or small amount of trade. Then, we can visualize the pattern and size of investment of one country compared to another. These can then be used by policy-makers to make an efficient policy decision.

The network analysis method has been applied by many scholars in the international trade network structure, but they are still limited to the following aspects: First, in the value chain-based research, most of the studies generally involve only two or several countries. According to the method of restrictions, value added trade can only do bilateral or multilateral trade association analysis, which cannot make a holistic and visual analysis of the global supply chain. Second, based on social network analysis, there are no scholars using value-added trade accounting methods to account for China's influence and position in the international network. Traditional total trade is not representative of a country's true level of trade; Third, in the social network research, most of the data are relatively old, such as that of Fagiolo et al. (2010) used data during the period 1981-2000, and the results of the study cannot be reflected in the current international trade pattern; Fourth, the current social network research is mostly in the unweighted network perspective such as that of Serrano and Boguna (2003) showed that the international trade had small world properties and only few countries control the world trade; Rauch and Watson (2004) found that international trade as an intermediary spreads in global network and has small world characteristics. Therefore, our study aims to expand and fill 
up the gap of network analysis in measuring the global value chain based on the network topology structure of the global trade network.

The network structure of international trade can be viewed from two perspectives binary and weighted networks. Binary networks can be used to analyze the characteristics of nodes in international trade networks. This method determines whether a trade relationship exists by setting a cut value. Generally, when the bilateral trade flow is greater than the cut value, the relationship is established and assigned a value of 1, and vice versa. Conversely, the weighted network can reveal the characteristics of the network. Obviously, in the global trade network we are concerned not only whether there is a trade link between countries, but we are more interested in the size of the trade between countries because it highlights the country's trade status. Due to the shortcomings of the binary network, our study will only concentrate on the weighted network.

The study is organized as follows. Section 2 is the literature review and section 3 presents the brief methodology of value added in trade. Section 4 will discuss the findings of the study. Finally, section 5 presents some concluding remarks.

\section{Literature Review}

The value added trade has been applied by Hummels et al. (2011) which estimates the value added situation of a country's foreign trade. Koopman et al. (2008, 2010, 2012) further deepen the value added algorithm where they divided a country's exports into domestic value added, direct foreign value added and indirect foreign value added; This method has also been used by the Johnson et al. (2012) and Koopman et al. (2014) to study the value added trade of countries around the world based on the WIOT database and showed that most of the countries' domestic value added nearly occupied $60 \%-80 \%$ of one countries' export, and different sectors had different percentages.

Dean et al. (2008) conducted research on the value added imported content in China's processing exports by using a Chinese input-output database to look at the years from 1997 to 2002. Their main result showed that international trade of China has become more specialized in the vertical direction where the vertical specialized (VS) share of China increased by nearly $23 \%$. The manufacturing sector, such as plastics, steel processing, industrial machinery, metal products, and electronic computers, were the most vertical specialized industries in China's international trade. In addition, they found that other Asian countries and territories, such as Japan, Taiwan, Korea, Singapore and Hong Kong, were main suppliers to China. The amount of China's import from these countries accounts for more than $50 \%$ of China's total imports.

Baldwin and Gonzalez (2013) developed the Hummel et al (2001) to decompose the sourcing patterns of intermediate imports used by China for US exports. Their findings showed that Japan, Taiwan and Korea stood out as main sourcing intermediated inputs countries for China exporting to the US. In addition, Koopman et al. (2014) and Dean et 
al. (2007) divided China`s total exports into processing exports and normal exports. They found that China's processing exports had less domestic value added compared to that in normal exports of China.

Most of the previous studies included China's trade position in a trade network, but there are some shortcomings due to data and method limitations. First, because of data constraints, the database that can be used to study value added include the WTO-OECD database which contains 62 countries, but with only discontinuous 7-year data, and the WIOT database which has data of 41 countries for 17 consecutive years. Both of these database have their own advantages and most of the research scholars use the WIOT database for data coherence, but the database includes fewer Asian countries, such as Malaysia, which is closely related to China's trade relations. Thus, their results are not perfect for China. Second, their method limitation restricts their overall picture of the global trade network or position.

Since the 1990s, social network theory has become a hot topic in the field of international trade. The concept of social networks originated in sociology and was later introduced into economics. Podolnyand Page (1998, p.59, cited in Rauch, 2001) defined the economic and social networks as a group of people with a group of people who have a long lasting relationship. Social networks have been a main mathematical tool for describing a complex system in the recent years, whose research scope involves social science, mathematics, physics, medicine, urban transportation, tourism network, economy, investment and banks. Compared with the traditional linear research method, social networks are defined as the actors and their relationships with each other. The social network embodies a structural relationship, and different types of relationships form different social networks. Point and line is the formal expression of social relationships, which can be expressed in graphs and matrices, and by studying the characteristics of graphs and matrices, some properties of social networks can be obtained.

With regards to the core-periphery structure of the World Trade Network, Snyder and Kick (1979) constructed an unlimited network with trade data in 1965, dividing 118 countries into core, semi-core and periphery countries, and noted that the core countries were almost all OECD member countries. Smith and White (1992) compared the coremarginal structure of 1965, 1970, and 1980, and noted that the core countries were increasing over time.

Wasserman and Faust (1994) put forward the concept of social networks and Newman (2003) reviewed and developed their study where he summarized several measurement indexes which can express the network topological properties, including the average shortest distance, node degree distribution, degree of aggregation, degree and so on. It has been used in many fields of economic research including the labor market, interbank markets, and technological regimes as well as for international business. Such as, Said (2015) conducted a research on measuring systemic risk based on network topology of 
bilateral exposures and obligations specifically for the sectorial level of global banking systems in 2010 .

Rauch (2001) imposed restrictions on the social networks in international trade. The network was originally produced in its own country and then passed through immigration or international direct investment into a cross-border network. In this way, international trade is in the maintenance of the network to run rather than create a network. He concluded that transnational social networks promote trade mainly in two ways. First, the asymmetric information makes the two sides meet the appropriate transaction before the search costs of finding new partners. The distance between the two sides and the existing business links directly affect the search process, so the search is more through the existing business contacts rather than through the open market. Social networks can provide trade information to their members, reducing search costs and matching costs. On the other hand, social networks can impose joint penalties on their members. When a member of the network violates the contract, his bad faith transaction will be quickly known by other members of the network, then, in the future we will not deal with him. When the discount of loss of future transactions is greater than the benefits of today's default, he will choose not to default. Such joint punishment mitigates the contractual problems caused by the weak enforcement of international trade laws and effectively curbs speculative defaults and facilitates trade.

Rauch and Trindade (2002) used a similar approach to validate the impact of Chinese networks on international trade. They argue that the Chinese network either increases trade by resolving contracts or increases trade by sharing business information. If the settlement is incomplete, there should be no difference in the impact of the trade between the low-difference product and the highly differentiated product trade. If the business information is shared, the impact on the trade of the highly differentiated product should be greater.

Wilhite (2001) pointed out that the choice mechanism of bilateral trade between countries in the world has formed a small world characteristic of the international trade network. In addition, Serrano and Boguna (2003) showed that international trade networks exhibit typical complex network characteristics, including scale-free distribution, small-world attributes, high aggregation coefficients and degree relationships among nodes. Using a complex network analysis method, Rauch and Watson (2004) examined the role of social networks in international trade and the availability of network intermediaries. They found that companies that could radiate were far more likely to become trading companies, while companies with a small range of trade radiation would choose to be direct producers of exports.

$\mathrm{Li}$ et al. (2003) also found that the international trade network has a scale-free feature in the establishment of an international trade network for trade relations with trade volume of over $\$ 1$ million in 2000. Rauch (1999, 2002), Wagner (2002), and Feenstra (2004) explored how transnational networks formed through immigration and international direct investment can promote international trade. They pointed out that a large number 
of immigrants and international investment played an important role in the international trade.

Fagiolo et al. (2010) used the weighted network approach to study the statistical characteristics and dynamic changes of the world trade network in 159 countries during the period 1981-2000, pointing out that trade relations in most countries were weak and some countries had strong trade relations, countries with close trade relations tend to trade relations with countries with loose trade relations, and rich countries have strong trade intensity and high aggregation factors. Fagiolo et al. (2008, 2009) showed that there is a difference between the weighted network analysis results and the no-power network analysis results. The weighted intensity of the weighted world trade network is shifted to the right.

Bhattacharya et al. (2008) have shown that the number of countries needed to control half of the world's trade is declining. Benedictis and Tajoli (2008) analyzed the characteristics of international trade by means of the network. The study showed that trade integration was far from complete except for individual regions, and the choice of national trading partners is quite heterogeneous.

Thus, our study will be based on the following: First, we will build a global social network trade model based on the value-added trade data, which not only reflects the real international trade pattern, but also can carry out the global analysis. Second, this study uses a weighted network model; trade volume as an important indicator of the measure, it is more able to reflect the country's position in the global value chain. Third, we use the value-added trade volume $\left(7\right.$ years $\left.{ }^{1}\right)$ that is provided in the WTO-OECD database which is also the most comprehensive and representative. It provides data on 62 countries, so it can give us a more comprehensive analysis of China and other countries' positions in the international trade network.

\section{Methodology}

\subsection{Data}

In this study, we use the $\mathrm{OECD}^{2}$ database for the period of $1995,2000,2005$, 2008, 2009, 2010 and 2011 to analyze the direct domestic value added exporting to a country.

The reason why we choose the OECD database is that it covers a wider range of countries. It provides data on 62 countries, which can give us a more comprehensive analysis on China's position in the international trade network. All the data is adjusted by

11995, 2000, 2005, 2008, 2009, 2010 and 2011.

${ }^{2}$ The Organization for Economic Co-operation and Development (OECD) is an intergovernmental, international economic organization of 35 market-oriented economies that aims to jointly address the economic and social consequences of globalization. The OECD entered into force in Paris on 30 September 1961 and was officially established by 35 Member States' parliaments, and has become the world's leading database. 
the Consumer Price Index from the US Department of Labor: Bureau of Labor Statistics. ${ }^{3}$

\subsection{Methodology}

3.2.1 Social Network Methodology

${ }^{3}$ We got CPI from www.bls.gov, and we assume CPI INDEX=100 in 1995, then based on 1995, we calculate relatively CPI INDEX. The results is 100(1995); 107.9(2000); 122.5(2005); 136.8(2008); 133.5(2009); 135.1(2010); 138.4(2011). 
The use of social network analysis to study world trade can not only describe the number of trading partners around the world, trade intensity, trade dispersion and concentration, but also can describe the pattern of world trade. Social networks are a collection of points (social actors) and connections between points (representing the relationship between actors).

Adjacency matrix method, which is commonly used in network analysis, is divided into the binary matrix which value are only 0 and 1 , and the multivalued matrix which value is the weighted value. In the trade network constructed in this paper, the nodes not only represent the trade relations between countries, but also the information represented by the size of the trade volume. The amount of trade between different countries has great disparity, and the countries have strong interaction with each other. Weak size (trade size) is a very important information for the study of the network, if only a simple binary network research can not truly reflect the actual state of trade between countries, which may miss the more important information. Therefore, this paper will use non-weighted network and weighted network to build social network modelrespectively.

First of all, an trade network matrix is represented by an $\mathrm{N} \times \mathrm{N}$ adjacency matrix. Each element of the matrix represents whether there is a trade relation between node $i$ and node j.

$X=\left[\begin{array}{ccccccc}0 & X_{12} & X_{13} & \ldots & X_{1 j} & \ldots & X_{1 n} \\ X_{21} & \ldots & \ldots & \ldots & \ldots & \ldots & X_{2 n} \\ \ldots & \ldots & 0 & \ldots & \ldots & \ldots & \ldots \\ \ldots & \ldots & \ldots & \ldots & \ldots & \ldots & \ldots \\ X_{i 1} & \ldots & \ldots & \ldots & 0 & \ldots & X_{i n} \\ \ldots & \ldots & \ldots & \ldots & \ldots & \ldots & \ldots \\ X_{n 1} & \ldots & \ldots & \ldots & X_{n j} & \ldots & 0\end{array}\right]$

In this matrix, $X_{i j}$ represents the true trade export value from country I to country $j$; the row means export and the column value means imports. Then we process matrix $\mathrm{X}$ to unweighted network and weighted network.

In an unweighted matrix $A$, if there is trade between the two countries, that is the export of country $i$ to country $j$ is greater than zero, $a_{i j}=1$, otherwise $a_{i j}=0$. 


$$
A=\left[\begin{array}{ccccccc}
0 & a_{12} & a_{13} & \ldots & a_{1 j} & \ldots & a_{1 n} \\
a_{21} & \ldots & \ldots & \ldots & \ldots & \ldots & a_{2 n} \\
\ldots & \ldots & 0 & \ldots & \ldots & \ldots & \ldots \\
\ldots & \ldots & \ldots & \ldots & \ldots & \ldots & \ldots \\
a_{i 1} & \ldots & \ldots & \ldots & 0 & \ldots & a_{i n} \\
\ldots & \ldots & \ldots & \ldots & \ldots & \ldots & \ldots \\
a_{n 1} & \ldots & \ldots & \ldots & a_{n j} & \ldots & 0
\end{array}\right]
$$

We select OECD data, there are 62 countries as our nodes. In order to make our result network easy to visualize and interpret, We process the data as follows:

1 if $\frac{F V A_{r}}{X_{r}}>0.01$ for each country $s \neq r=1,2, \ldots \mathrm{N}$

$a_{s r}=$

0 otherwise

Where $a_{i r}=\frac{F V A_{i r}}{X_{r}}$ represents the rate of FVA to total export. More value of $a_{i r}$ is, more important supplier is of valued in one country's exports.If $a_{s r}>0.01$, indicating a close relationship between the two countries,then, the unweighted network of value added trade among countries is established.

Next, we construct a weighted network matrix $\mathrm{W}$ on the basis of an unweighted network, where the elements are denoted by the import and export trade values of country $i$ and country $j$

$w_{i j}^{t}=\left(a_{i j}^{t}+a_{j i}^{t}\right) / 2$

where $a_{i j}^{t}$ and $a_{j i}^{t}$ are bilateral trade import and export volume of country $i$ and country $j$ in the matrix $\mathrm{X}$

$W=\left[\begin{array}{ccccccc}0 & w_{12} & w_{13} & \ldots & w_{1 j} & \ldots & w_{1 n} \\ w_{21} & \ldots & \ldots & \ldots & \ldots & \ldots & w_{2 n} \\ \ldots & \ldots & 0 & \ldots & \ldots & \ldots & \ldots \\ \ldots & \ldots & \ldots & \ldots & \ldots & \ldots & \ldots \\ w_{i 1} & \ldots & \ldots & \ldots & 0 & \ldots & w_{i n} \\ \ldots & \ldots & \ldots & \ldots & \ldots & \ldots & \ldots \\ w_{n 1} & \ldots & \ldots & \ldots & w_{n j} & \ldots & 0\end{array}\right]$ 
In order to make all the values $w_{i j}^{t} \in[0,1]$, all the values in the matrix $\mathrm{W}$ divided by the maximum value, while this does not affect the final analysis results.

We combine the unweighted network and weighted network to comprehensive analysisvalue added trade among countries.In this paper, the visualization structure is drawn for the trade network, and the network is characterized by network density, centrality, network intensity, network correlation (QAP), graph of network density distribution, cohesive subgroup and core edge structure,etc to describe our network, the main use of network analysis software is Ucinet6 for calculation and mapping.

The use of social network analysis to study world trade cannot only describe the number of trading partners around the world, trade intensity, trade dispersion and concentration, but also can describe the pattern of world trade. Social networks are a collection of points (social actors) and connections between points (representing the relationship between actors).

The adjacency matrix method, which is commonly used in network analysis, is divided into the binary matrix has values of only 0 and 1 , and the multivalued matrix in which the value is the weighted value. In the trade network constructed in this study, the edges not only represent the trade relations between countries, but also the information represented by the size of the trade volume. The amount of trade between 62 countries has great disparity. The size of the trade has very important information for the study of the network; it cannot truly reflect the actual state of trade between 62 countries with only a simple binary network which may miss the more important information. Therefore, this study will use a weighted network to build a social network model.

Trade network matrix is represented by an $\mathrm{N} \times \mathrm{N}(62 \times 62)$ adjacency matrix, In this matrix, $X_{i j}$ represents the true trade export value (DVA) from country $i$ to country $j$; the row is exports and the column value is imports.

$$
X=\left[\begin{array}{ccccccc}
0 & X_{12} & X_{13} & \ldots & X_{1 j} & \ldots & X_{1 n} \\
X_{21} & \ldots & \ldots & \ldots & \ldots & \ldots & X_{2 n} \\
\ldots & \ldots & 0 & \ldots & \ldots & \ldots & \ldots \\
\ldots & \ldots & \ldots & \ldots & \ldots & \ldots & \ldots \\
X_{i 1} & \ldots & \ldots & \ldots & 0 & \ldots & X_{i n} \\
\ldots & \ldots & \ldots & \ldots & \ldots & \ldots & \ldots \\
X_{n 1} & \ldots & \ldots & \ldots & X_{n j} & \ldots & 0
\end{array}\right]
$$

Then we process matrix $\mathrm{X}$ to weighted network W. In order to make all the values $w_{i j}^{t} \in[0,1]$, all the values in the matrix $W$ are divided by the maximum value of $X_{i j}$, and this does not affect the final analysis results. 


$$
W=\left[\begin{array}{ccccccc}
0 & w_{12} & w_{13} & \ldots & w_{1 j} & \ldots & w_{1 n} \\
w_{21} & \ldots & \ldots & \ldots & \ldots & \ldots & w_{2 n} \\
\ldots & \ldots & 0 & \ldots & \ldots & \ldots & \ldots \\
\ldots & \ldots & \ldots & \ldots & \ldots & \ldots & \ldots \\
w_{i 1} & \ldots & \ldots & \ldots & 0 & \ldots & w_{i n} \\
\ldots & \ldots & \ldots & \ldots & \ldots & \ldots & \ldots \\
w_{n 1} & \ldots & \ldots & \ldots & w_{n j} & \ldots & 0
\end{array}\right]
$$

We combine the weighted network's properties to the comprehensive analysis value added trade among 62 countries. In this study ${ }^{4}$, the visualization structure is drawn for the trade network, and the network is characterized by network density, centrality, network correlation, graph of network density distribution, and core periphery structure.

Network density is an indicator of the degree of intimacy between nodes in a network. It is a description of the overall network situation. The density of the algorithm is rate of the "actual total number of relationships" and "theoretically possible maximum number of relationships", Which is in fact equal to the average of all possible relationships. In this paper, the term "relationship" refers to the links between 62 countries arising from trade between them. The density of the trade network can reflect the close degree of trade links among the main nodes in the network. The closer the density is, the closer the network is. The higher the overall network development, the more smooth of resources transmission and information flow in the network. The smaller the network density, the more loose the relationship between the various countries in the network, if the relationship is more alienated, it may be detrimental to the development of network members. The equation of density is as follows:

$D=\frac{L}{m(m-1)}$

Where $L$ is the number of lines in the network and $m$ is the number of nodes in the network

4. Empirical Results

4.1 Global Trade Network Characteristic

4.1.1 Basic Description of Global Trade Network

${ }^{4}$ The main use of network analysis software is UCINET6 for calculation and mapping. 
Table 1 shows the descriptive analysis of the overall pattern of the global trade network for the seven years data. The number of edges increased from 632 to 742 from year 1995 to 2011. Similarly, the clustering coefficient increased from 0.986 to 0.993 for the same year. This means the global network is still have high clustering property. In addition, the value of the mean, standard deviation and the sum all increased between the years. However, the value for variance initially had an upward trend between 2.886 and 6.237 in 1995 and 2009, respectively and slightly declined to 5.959 in 2011. Our result on heterogeneity of the network shows fluctuation during the seven years of analysis. This shows that the whole global network first had more disparity and then maybe after the economic crisis in 2009, some economies did not recover in time, so trade is still concentrated in some countries. According to May (1972) the value of the eigenvalue should be between zero to one to show the stability of the network analysis. Our results show that the eigenvalues are less than one for all years of analysis.

Table 1: The Network Results of Global Value Added Trade In 7 Years

\begin{tabular}{|c|c|c|c|c|c|c|c|}
\hline & 995 & 000 & 005 & 008 & 009 & 010 & 011 \\
\hline Edges & 32.00 & 40.00 & 08.00 & 96.00 & 734.00 & 712.00 & 742.00 \\
\hline CC & .986 & .990 & .991 & .993 & .994 & .993 & .993 \\
\hline Mean & .093 & .046 & .198 & .553 & .738 & .695 & .704 \\
\hline Std Dev & .699 & .729 & .795 & .243 & .497 & 441 & .441 \\
\hline Sum & 7.771 & 4.861 & 4.283 & 6.264 & 07.762 & 05.096 & 05.648 \\
\hline Variance & .886 & .991 & .220 & .030 & .237 & .959 & .959 \\
\hline SSQ & 52.988 & 53.282 & 88.662 & 61.306 & 73.981 & 47.578 & 49.458 \\
\hline MCSSQ & 78.908 & 85.428 & 99.663 & 11.842 & 86.681 & 69.431 & 69.432 \\
\hline Minimum & .018 & .021 & .027 & .036 & .044 & .034 & .027 \\
\hline Maximum & .553 & 0.960 & 0.446 & 1.787 & 2.903 & 2.504 & 2.145 \\
\hline $\begin{array}{l}\text { Network } \\
\text { Centralization }\end{array}$ & $.74 \%$ & $0.24 \%$ & $.56 \%$ & $0.58 \%$ & $1.54 \%$ & $1.17 \%$ & $0.79 \%$ \\
\hline $\begin{array}{ll}\text { y } & \text { Heterogeneit } \\
\end{array}$ & $.51 \%$ & $.02 \%$ & $.23 \%$ & $.98 \%$ & $.94 \%$ & $.96 \%$ & $.92 \%$ \\
\hline Skewness & .3 & .3 & .4 & .44 & .47 & .6 & .62 \\
\hline Kurtosis & .69 & .78 & .65 & .512 & .43 & .434 & .439 \\
\hline Eigenvalue & .072 & .067 & .071 & .073 & .075 & .074 & .074 \\
\hline
\end{tabular}

Source: calculated by author based on the WTO-OECD with UCINET 6 between 1995 and 2011. 


\section{Mapping the Global Trade Network}

In order to get a clearer view of the change of the trade network structure, we show visualizations of the network with 100 numbers of iteration as shown in figures 1 to 7 for 1995, 2000, 2005, 2008, 2009, 2010 and 2011. We set a threshold value of 0.05. Thus, if the total amount of imports and exports between the two countries exceeds the threshold value, then the trade is strongly interconnected. If the value does not exceed the threshold, it is shown that trade is less interconnected. It shows that the thicker the link, the greater the volume of trade between the two countries. The number of links in 1995 and 2011 are 174 and 202, respectively. Through the visualization, it shows that the global trade network is becoming more interconnected in 2011 as shown in figure 7 . In 1995, the core countries of the world trade were the United States, the United Kingdom, Germany, France, Japan, and China. In 2011, it has shown that China became the core country in the core-periphery followed by other countries such as India, France, and South Korea. China surpassed Japan to become Asia's largest trading country in 2011.

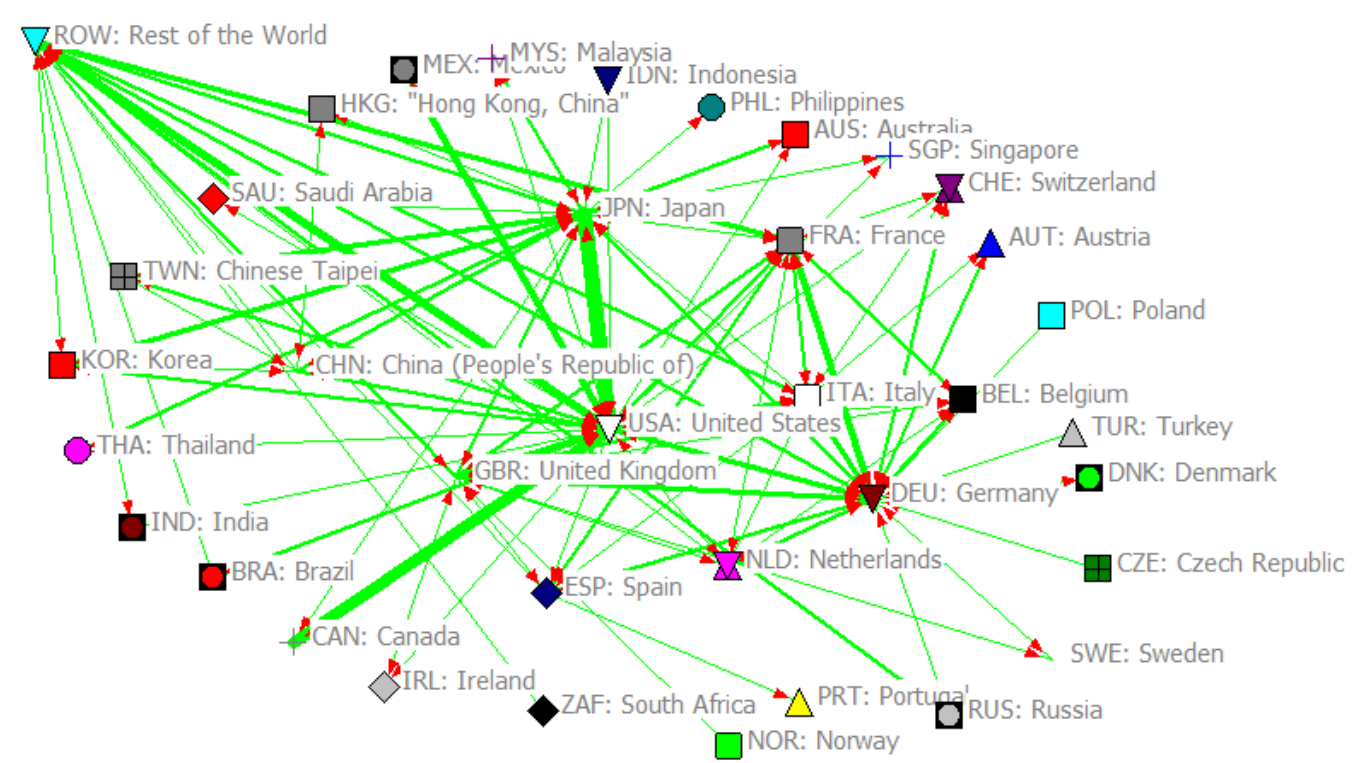

Figure 1: Visualization of Global Value Added Trade in 1995 


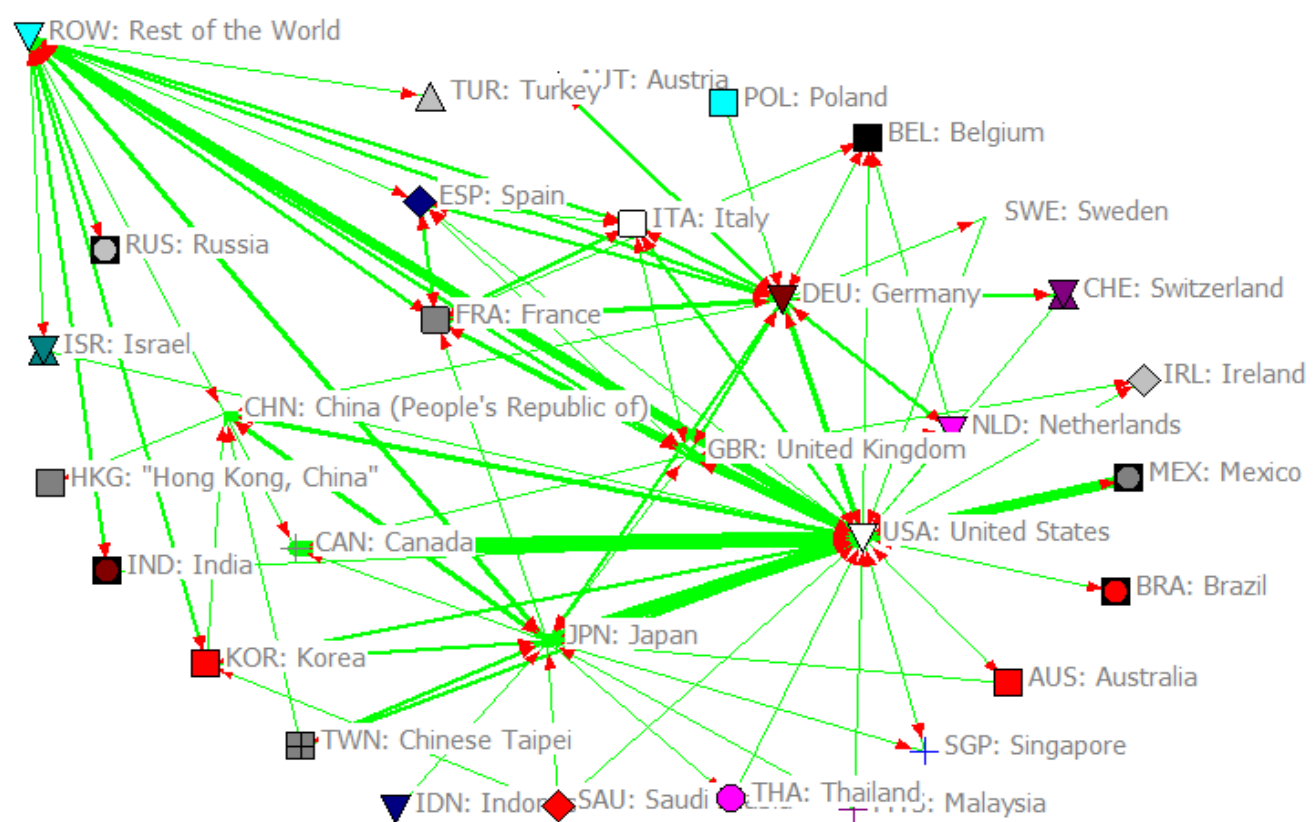

Figure 2: Visualization of Global V alue Added Trade in 2000

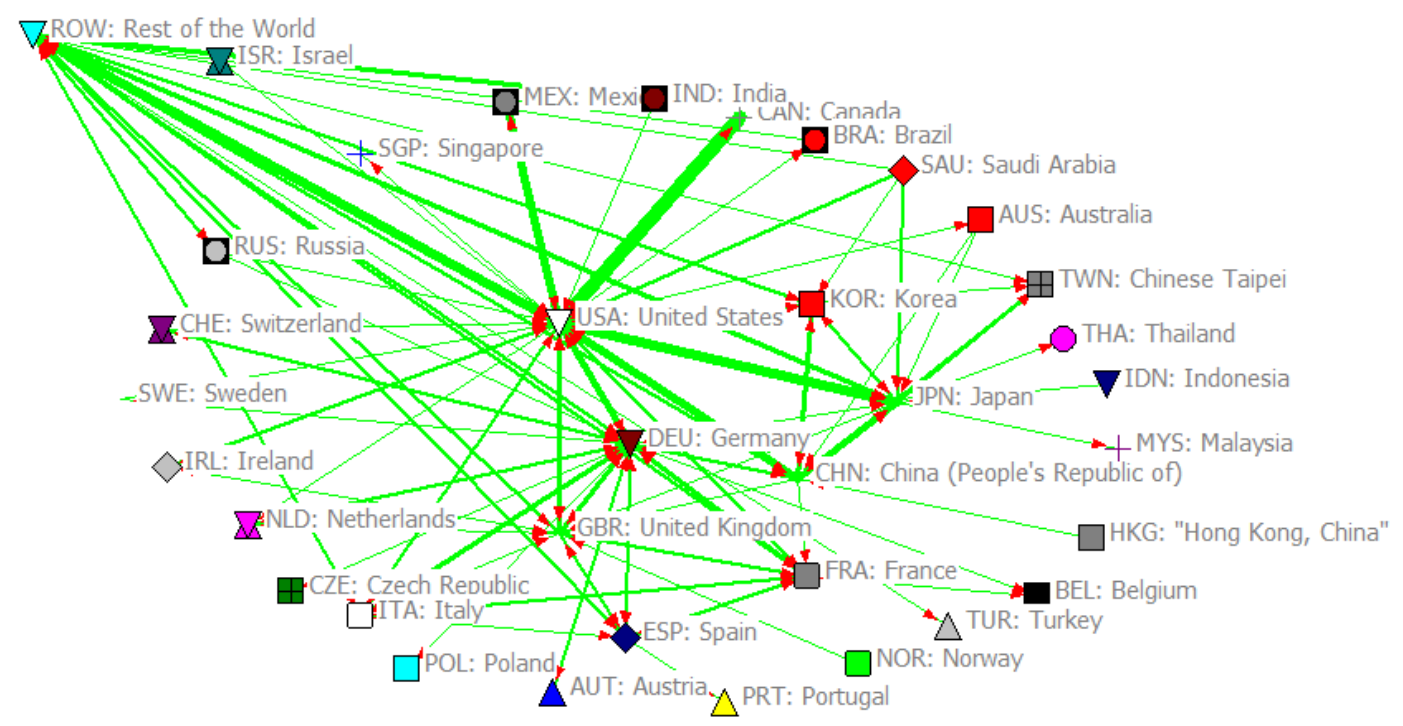

Figure 3: Visualization of Global V alue Added Trade in 2005 


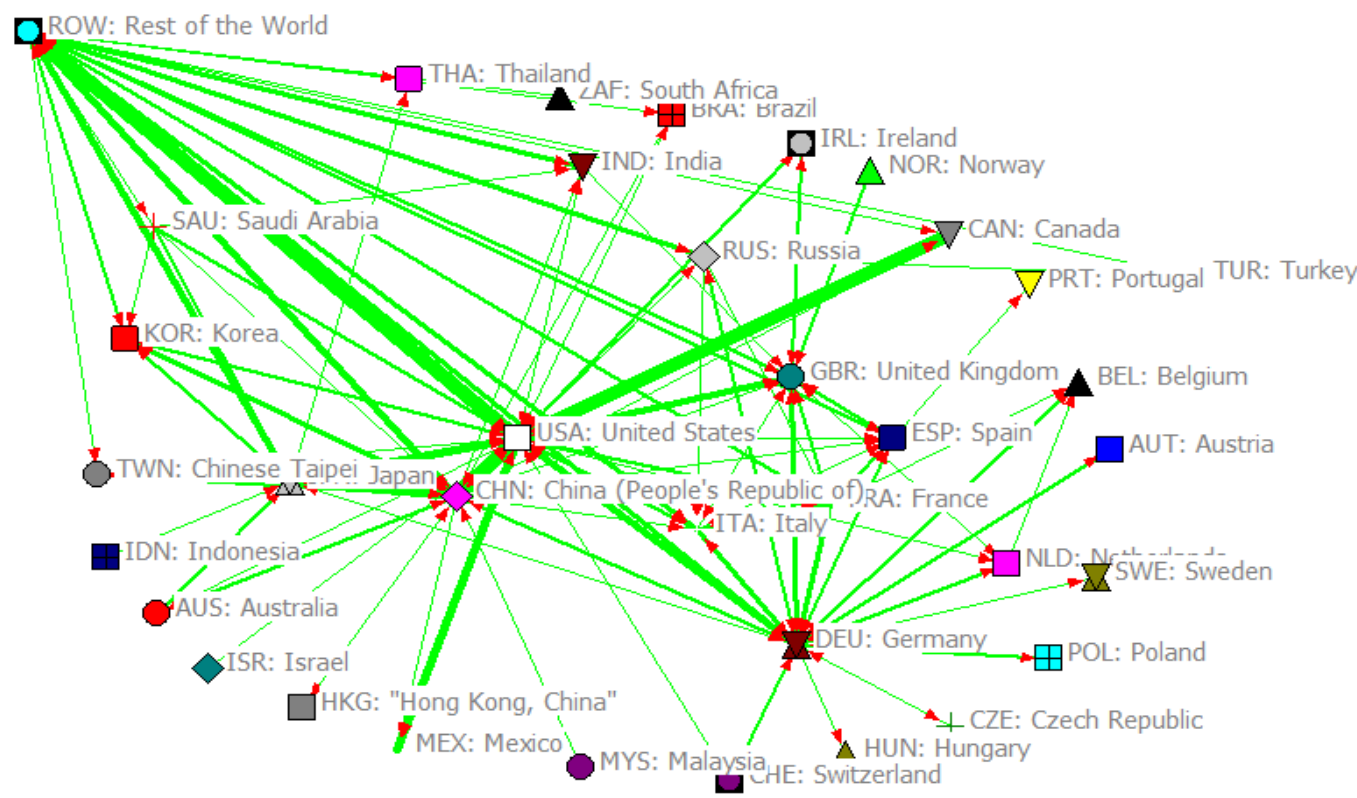

Figure 4: Visualization of Global V alue Added Trade in 2008

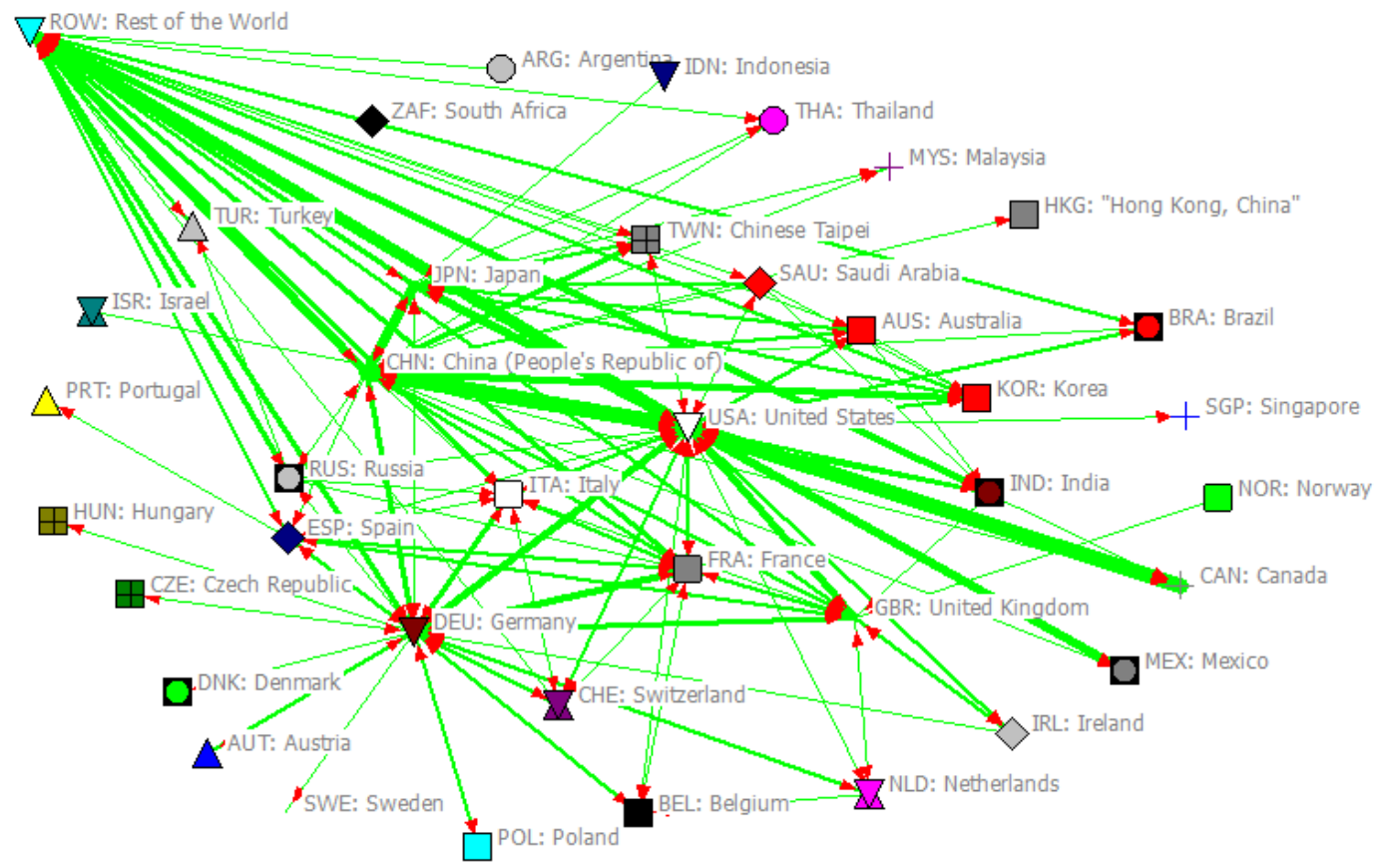

Figure 5: Visualization of Global V alue Added Trade in 2009 


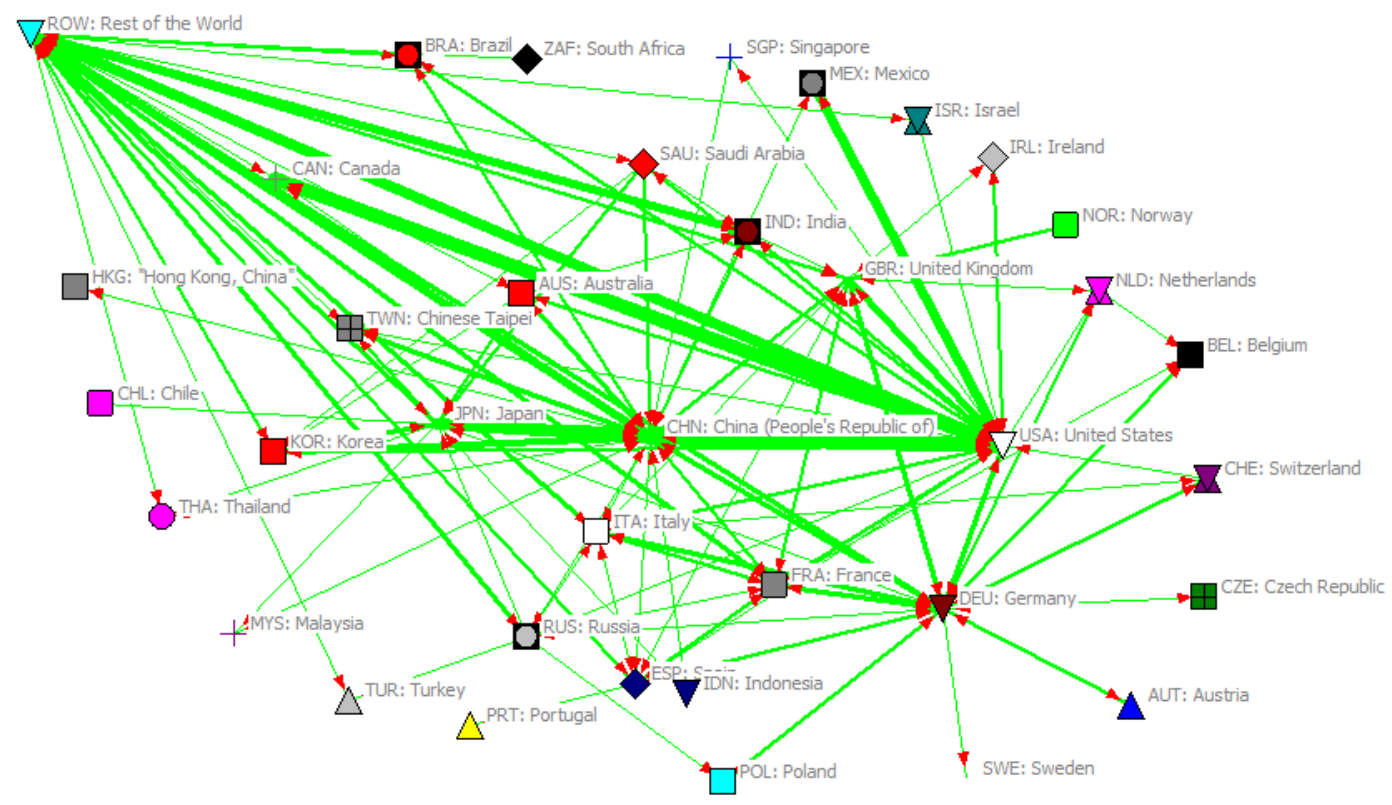

Figure 6: Visualization of Global V alue Added Trade in 2010

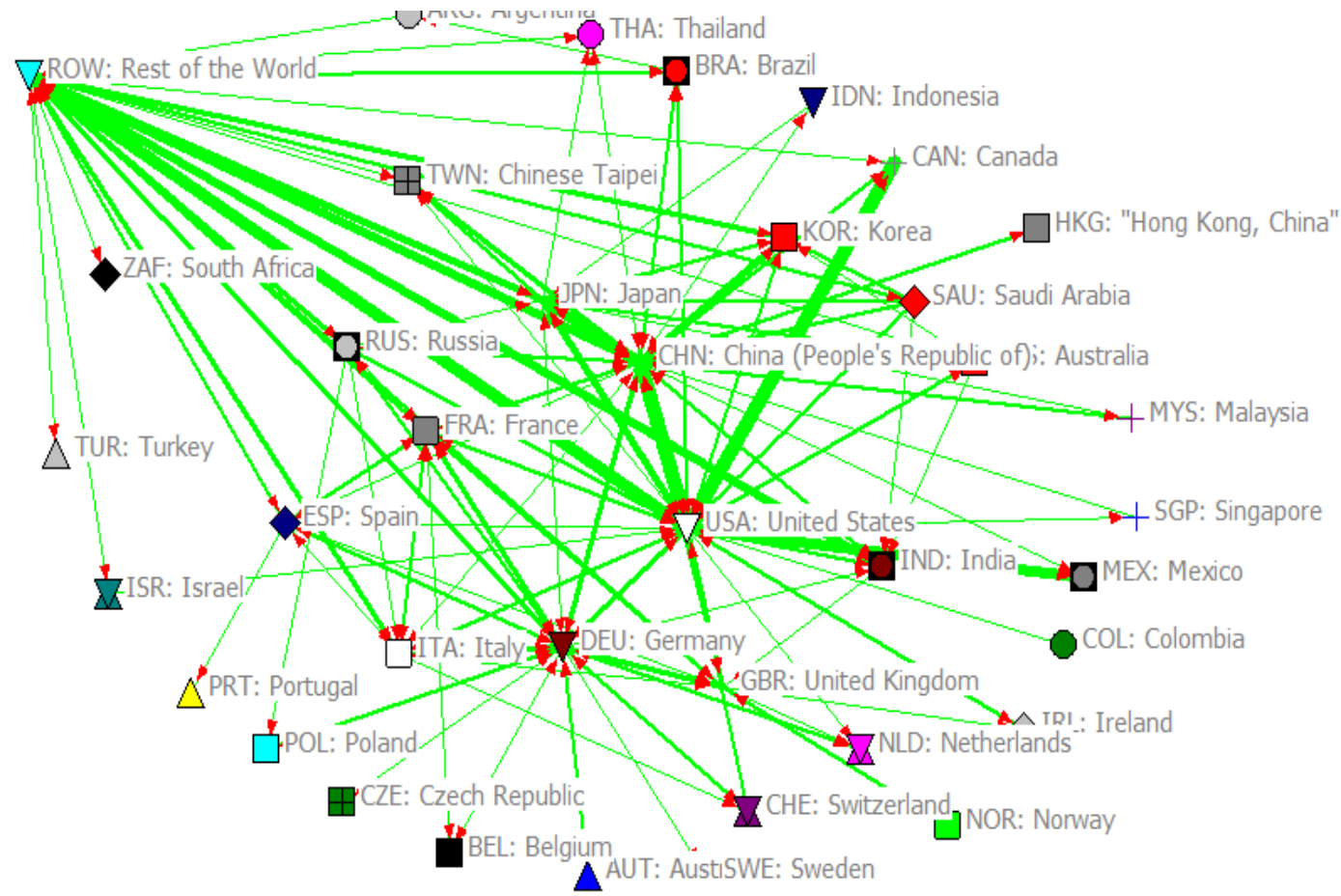

Figure 7: Visualization of Global Value Added Trade in 2011 


\section{Conclusions}

This paper explored global trade network and specifically China's position in the international trade system from the perspective of complex networks from the centrality, core-edge structure and eigenvalues. The measurement and evaluation provide a reference in order to understand the global trade network and China's position in international trade.

First, with economic globalization, China, Russia, India, and Saudi Arabia had a rapid growth of international trade. South Korea, Hong Kong (China), Taiwan (China), Australia, Malaysia, Indonesia, South Africa and other developing countries (regions) also progress significantly. The traditional international trade power status of North America, the UK, France and other countries are still very stable.

Second, from 1995 to 2011, China's trade partners have been increasing continuously and its centrality has been continuously promoted. The competitiveness of import and export trade has also been on the rise. By 2011, its trade competitiveness was in the second position of world trade. The disparity of imports and exports of China has also been improved, the trade destinations are more dispersed, and the ranking of the eigenvalue of China increased from the world's 11th to the world's second position. China as a trade "core" role has been improved, and in 2011 became the first core country. All the indices and China's trading partners also highlight China's important position in international trade. The results showed a good correspondence with the Chinese reality, and reflected the status and influence of China in all aspects from the quantitative measures that were used.

Third, China still needs time to move from being a large trading volume to a more international trading power. From the analysis of this study, China has become the core trading power, but its trade competitiveness and trade disparity still have big gaps between the United States, Germany, the UK, Japan and other developed countries. The performance of these developed countries are very stable. We also know that the manufacturing industry is still the main profit source for China. Thus, in our future research, we will deepen our focus on the position and influence of China's various industries' network analysis.

\section{References}

Albert, R. and Barabási, A. L., (2002). "Statistical Mechanics of Complex Networks", Reviews of Modern Physics, Vol.1, pp.47.

Baldwin, Robert (1993). The New Protectionism: A Response to Shifts in National

Economic Power. In Jeffrey A. Frieden and David A. Lake (eds.), International

Political Economy, 339-58. London: Routledge.

Baldwin, R., (2012). "Global Supply Chains: Why They Emerged, Why They Matter, and Where They Are Going" Centre for Trade and Economic Integration (CTEI) Papers, 2012- 132012

Baldwin, R and Gonzalez, L., (2013). "Supply-Chain Trade: A Portrait of Global Patterns and Several Testable Hypotheses" NBER Working Paper Series 18957

Barabasi, Alberto-Laszlo (2003). Linked: How Everything is Connected to Everything Else and What it Means. New York: Plume Book. 
Batagelj, Vladimir and Andrej Mrvar (2011). Pajek 2.04. Free software for social network analysis available at http://pajek.imfm.si/doku.php?id=download, 13.1.2015.

Borgatti, P. Stephen and Pacey C. Foster (2003). The Network Paradigm in Organizational Research: A Review and Typology. Journal of Management 29 (6):991-1013.

Burt, R. S., (1992). Structural Holes: The Social Structure of Competition, Harvard University Press.

Dean, J. M., Fung, K. C., and Wang, Z., (2008). "Measuring the Vertical Specialization in Chinese Trade" Office of Economics Working Paper, No. 2007-01-A, U.S. International Trade Commission

Fagiolo, Giorgio, Javier A. Reyes and Stefano Schiavo (2007). International trade

and financial integration: a weighted network analysis. OFCE Working Paper

No. 2007-11, 1-21.

Fagiolo, G., Reyes, J. and Schiavo, S., (2009). "World trade Web: Topological Properties, Dynamics and Evolution", Physical Review, Vol. 79, pp.1-19.

Fagiolo, G., Reyes, J. and Schiavo, S., (2010). “The Evolution of the World Trade Web: A Weighted-network Analysis", Journal of Evolutionary Economics, Vol.20, pp.479-514.

Freeman, C. Linton (1978). Centrality in social networks. Social Networks 1 (1): 215-39.

Freeman, C. Linton (2004). The Development of Social Network Analysis: A Study

in the Sociology of Science. North Charleston, SC: Book Surge.

Fulik, Janet (2001). Global network organizations: Emergence and future prospects.

Human Relations 54 (1): 91-99.

Goyal, Sanyeev (2009). Connections: An introduction to the Economics of Networks. 2nd ed. Princeton and Oxford: Princeton University Press.

Goyal, Sanyeev (2011). Social Networks in Economics. In Peter J. Carrington and

John Scott (eds.), The SAGE Handbook of Social Network Analysis, 67-79.

London: SAGE Publications.

Hummels, D., Ishii, J., and Yi, K. M., (2001). "The Nature and Growth of Vertical Specialization in World Trade" Journal of International Economics, 54: 75- 96

Hidalgo, A. Cesar and Ricardo Hausmann (2008). A network view of economic development. Developing alternatives 12 (1): 5-10.

Hidalgo, A. Cesar and Ricardo Hausmann (2009). The building blocks of economic

complexity. PNAS 106 (26): 10570-575.

Haile F,Pozo S. (2008). Currency crisis contagion and the identification of transmission channels [J]. International Review of Economics \& Finance, 17(4): 572-88

Inomata, S., (2013). "Trade in Value Added: An East Asian Perspective" ADBI Working Paper Series No.451

Jackson, O. Matthew (2008). Social and Economic Networks. Princeton and Oxford:

Princeton University Press.

Johnson, R. C., Noguera, G., (2012). “Accounting for Intermediates: Production Sharing and Trade in Value Added, Journal of International Economics, 86 (2), 224- 236.

Johnson, R.C., (2014). "Five Facts about Value-Added Exports and Implications for Macroeconomics and Trade Research" Journal of Economic Perspectives, 28 (2)119-142.

Kilduff, Martin, Wenpin Tsai and Ralph Hanke (2006). A paradigm too far? A dynamic stability reconsideration of the social network research program.

Academy of Management Review 31 (4): 1031-48.

Koopman, R., Wang, Z., Wei, S., (2008). "How much of Chinese Exports is Really Made in China? Assessing Domestic value-added when processing trade is pervasive" NBER Working paper, No. 14109

Koopman, R., Wang, Z., Wei. S., (2010). "Give Credit Where Credit Is Due: Tracing Value Added in Global Production Chains” NBER Working Paper, No. 16426.

Koopman, R., Wang, Z., Wei. S., (2012). "Tracing Value-Added and Double Counting in Gross Exports" American Economic Review, 104(2): 459- 94.

Koopman, R., Wang, Z., Wei. S., (2014). "Tracing Value-Added and Double Counting in Gross Exports" American Economic Review, 104(2): 459- 94.

Krugman, R. Paul (1980). Scale economies, Production differentiation, and Pattern of Trade. American Economic Review 70 (5): 950-59.

Lall, S., Weiss, J. and Oikawa, H., (2005). "China's Competitive Threat to Latin America: an Analysis for 1990-2002”, Oxford Development Studies, Vol. 33, pp.163-194. 
Li, X., Jin, Y. Y. and Chen, G., (2003). "Complexity and Synchronization of the World Trade Web", Physica A: Statistical Mechanics and its Applications, Vol. 328, pp.287-296.

Lorrain, Francois and Harrison C. White (1971). Structural equivalence of individuals

in social networks. Journal of Mathematical Sociology 1 (1): 49-80.

May, Robert M. (1972). Will a large complex system be stable. Nature, 238, 413-414.

Opsahl, Tore (2009): Structure and evolution of weighted networks. London: University of London.

Opsahl, Tore, Filip Agneessens and John Skvoretz (2009). Node centrality in weighted networks: (2): 245-51.

Generalizing degree and shortest path. Social Networks 32

Podolny, M. Joel (2001). Networks as the Pipes and Prisms of the Market. The American Journal of Sociology 107 (1): 33-60.

Rauch, E. James (1999). Networks versus markets in international trade. Journal of

International Economics 48 (1): 7-35.

Rauch, J. E., (2001). "Business and Social Networks in International Trade", Journal of Economic Literature, Vol. 39, pp.1177-1203.

Said, Fathin Faizah, (2015). Global Banking on the Financial Network Modeling: Sectorial Analysis. Computational Economics, Vol. 46, 1-27.

Scott, J., (2000). Social Network Analysis, A Handbook, Sage Publications Ltd.

Serrano, M. Á. and Boguñá, M., (2003). "Topology of the World Trade Web”, Physical Review E, Vol. 68, pp.634-646.

Smith-Doerr, Laurel and Walter W. Powell (2005). Networks and Economic Life.

In Neil J. Smelser and Richard Swedberg (eds.), The Handbook of Economic Sociology, 379-402. New York: Russell Sage Foundation.

Squartini, T., Fagiolo, G. and Garlaschelli, D., (2011). "Randomizing World Trade. II. A Weighted Network Analysis", Physical Review E, Vol.84, pp. 046-118.

Tong, Xin and Reid Lifset (2007). International copper flow network: A blockmodel

analysis. Ecological Economics 61 (2-3): 345-54.

Wasserman, S. and Faust, K., (1994). Social Network Analysis: Methods and Applications, Cambridge University Press. 